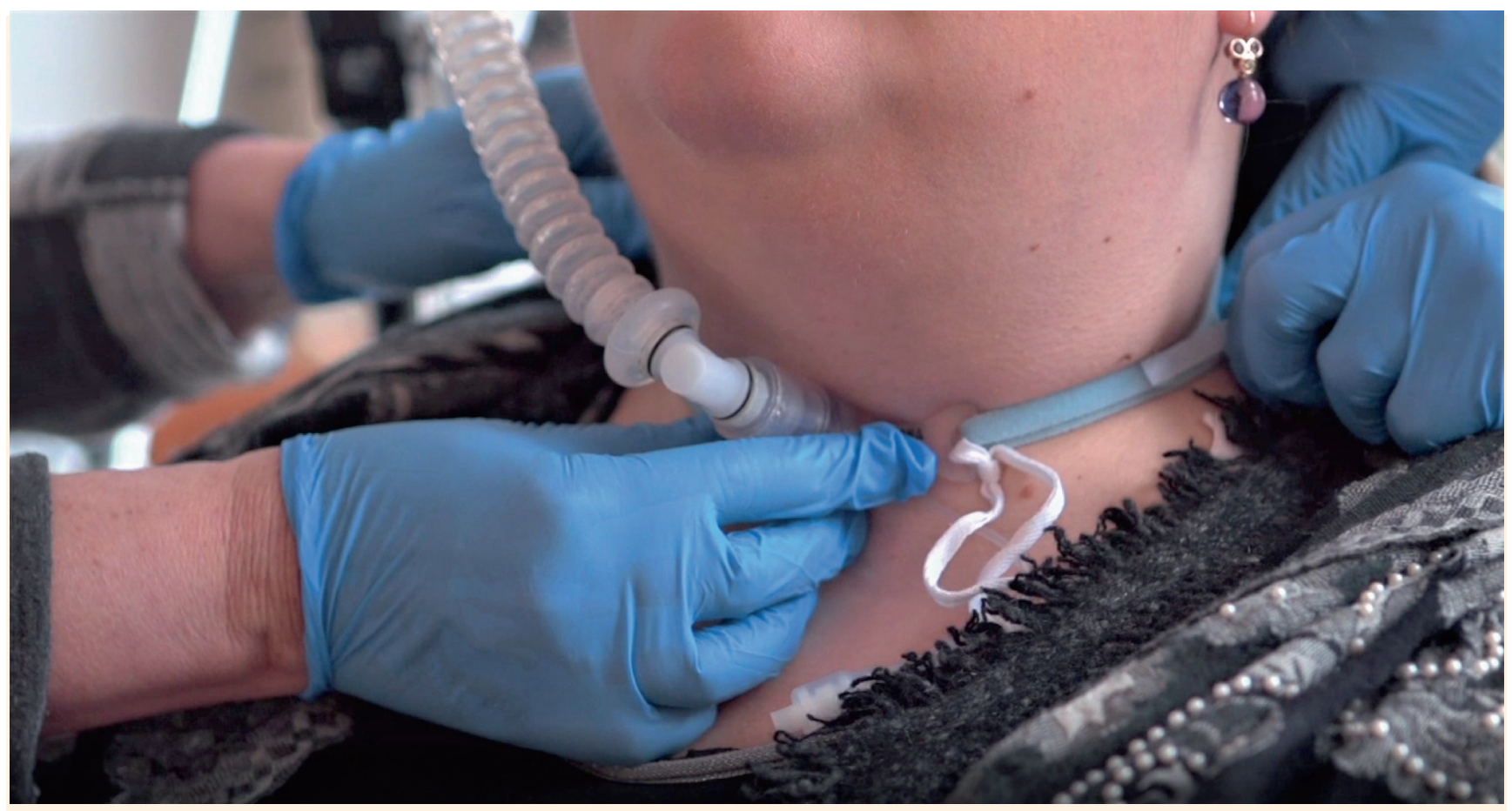

\title{
Verzorgen en aspireren van \\ een tracheacanule
}

Sommige patiënten komen op de verpleegafdeling (of thuis) met een tracheostoma en tracheacanule. Hoe verzorg je die en waar let je op bij het aspireren?

tekst Els Put fotografie Onderwijsprogramma Chronische beademing: www.ctbscholing.nl

ommige covid-19-patiënten krijgen op de intensive care een tracheacanule voor beademing, die ze nog hebben als ze verhuizen naar een verpleegafdeling. 'Niet altijd weten verpleegkundigen op die afdeling hoe ze zo'n tracheacanule moeten verzorgen', mailden lezers ons. Leen Backaert, hoofdverpleegkundige op de neus-keel-oor-afdeling van UZ Leuven, campus Gasthuisberg, herkent dat: 'We zien regelmatig revaliderende ex-covid-patiënten op onze afdelingen. Zij hebben meestal een tijdelijke tracheacanule, die we tijdens hun verblijf op de revalidatieafdeling proberen af te bouwen. Dat verloopt met wisselend succes. Daarnaast kunnen ook patiënten met een oncologische aandoening in de hoofd- 


\section{VERZORGING WOND EN REINIGEN INWENDIGE TRACHEACANULE}

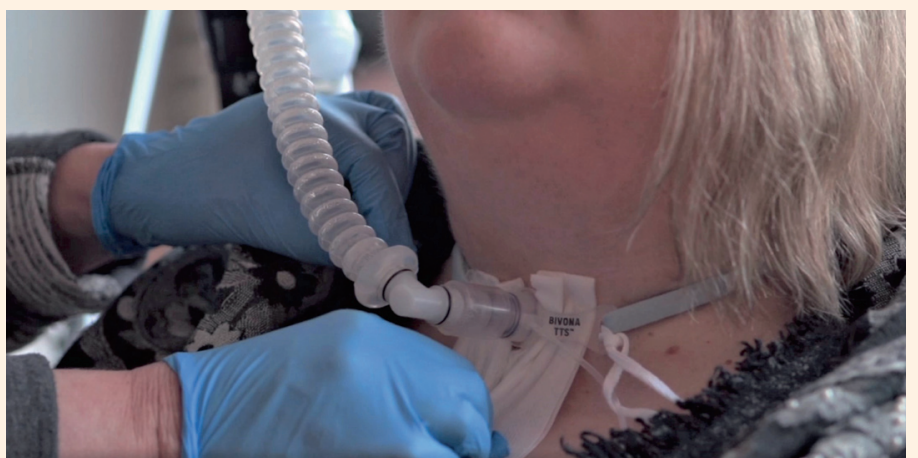

- Was en ontsmet je handen, en doe niet-steriele handschoenen aan volgens protocol van je organisatie. Verzamel de materialen. Informeer en installeer de zorgvrager. Vraag in de wijk zo nodig/ mogelijk de mantelzorger om assistentie.

- Bij een luchtgecuffte canule: controleer de druk in de cuff met een cuffdrukmeter.

- Maak het fixatiemateriaal losser zodat je onder het plaatje rond de tracheacanule kan, verwijder binnencanule, kunstneus, spreekknopje, beademingsslang of afsluitdopje en splitgaas.

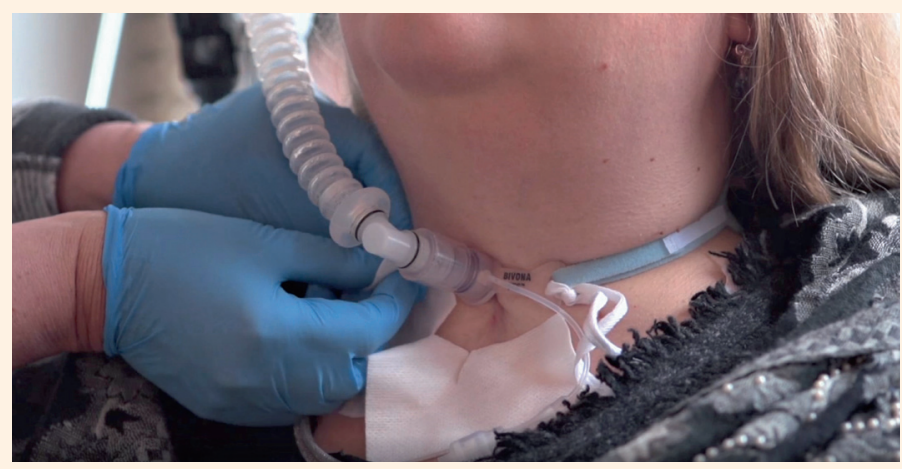

- Leg de inwendige canule in een opvangbakje met een waterige oplossing. (Thuis meestal water, in het ziekenhuis een waterige ontsmettingsvloeistof). Bij infectie gebruik je een alcoholische oplossing.

- Breng voorzichtig een schone, inwendige canule in. Plaats kunstneus, spreekknopje, en beademingsslang of afsluitdopje terug.

- Breng indien nodig een splitgaas aan rond de tracheacanule en pas het fixatiemateriaal (tracheacanulebandje, klittenbandje, lintje) weer aan.

\section{Materialen wondzorg}

- Niet steriele handschoenen, mondmasker, spatbril

- Niet steriele gaasjes, wattenstokjes, pincet

- Reservecanule

- Noodcanule indien voorgeschreven

- Metalline of splitgaas

- Canulebandje

- Huidbeschermingsmiddel

- Afvalbakje

hals-regio een tracheacanule hebben om hun luchtweg veilig te stellen als die bedreigd wordt. Soms wordt daarbij het strottenhoofd verwijderd.'

Sander Steijns, verpleegkundig specialist thuisbeademing in de regio Nijmegen/Tilburg/Maastricht voegt toe dat het ook mogelijk is ex-covid19-patiënten met een tracheacanule thuis te verzorgen: 'Bijvoorbeeld voor nachtelijke beademingsondersteuning.'

\section{Stoma en canule}

Afhankelijk van de onderliggende pathologie krijgt de patiënt een gecuffte of ongecuffte, een gevensterde of ongevensterde, een tijdelijke of permanente tracheacanule.

Een tracheacanule met cuff is nodig bij moeilijk te beademen patiënten en bij patiënten met slikproblemen, omdat zij een verhoogd risico hebben op aspiratie van vocht in de luchtweg. De cuff voorkomt dat.

Bij patiënten met een dwarslaesie of spierziekte, of oncologische patiënten bij wie het strottenhoofd gespaard is gebleven, heeft een gevensterde/ ongecuffte canule de voorkeur. Een gevensterde canule heeft een opening in de bocht van de canule zodat een patiënt met een strottenhoofd nog kan praten.

Een patiënt zonder strottenhoofd krijgt een ongevensterde canule. Hij kan met een stemknopje op de tracheacanule leren praten. Wanneer een stemknopje niet nodig is, wordt vaak een kunstneus op de tracheaca- nule geplaatst. Deze is bedoeld om de geïnhaleerde lucht te bevochtigen, omdat koude en ongefilterde lucht kan zorgen voor irritatie en extra slijm in de longen.

Een patiënt heeft weinig hinder van een tracheacanule, behalve bij het manipuleren tijdens de wondzorg en bij het aspireren/uitzuigen. Die handelingen geven een hoestprikkel en benauwdheid. Daarmee komen we bij het eerste aandachtspunt: let erop dat de patiënt tijdens je zorg de canule niet uithoest, want een tracheostoma kan dichtklappen en dan heeft de patiënt geen vrije luchtweg meer.

\section{Vervanging canule}

In dit artikel bespreken we de zorg rond tracheostoma en tracheacanule buiten de afdeling intensieve zorgen/ intensive care. 'Anders dan bij beademde patiënten op intensieve zorgen is de zorg voor de tracheostoma en het aspireren van de tracheacanule op onze afdeling een niet-steriele handeling,' aldus Leen Backaert. 'We 


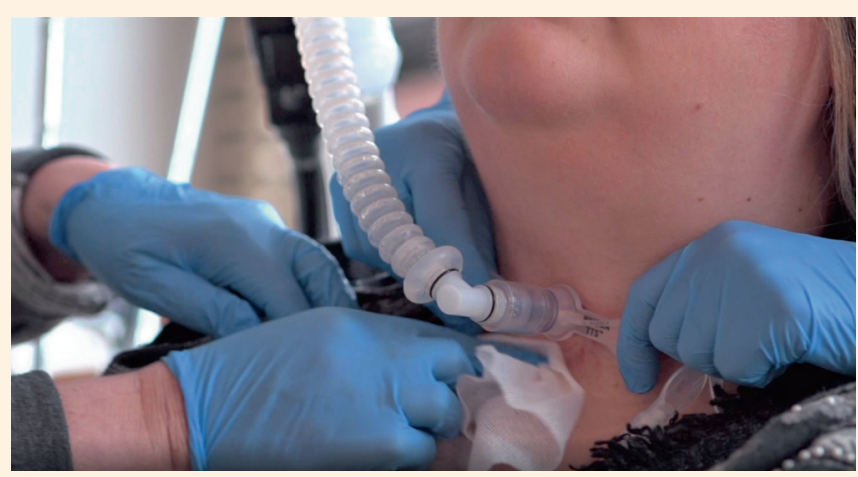

- Reinig de wondranden met een fysiologische of een waterige ontsmettingsvloeistof (bijvoorbeeld chloorhexidine) en dep droog. Controleer de huid rondom de stoma op roodheid, irritatie en wild vlees. Tijdens de wondzorg hou je de canule vast om te voorkomen dat deze inwendig beweegt en daardoor een hoestreflex oproept.

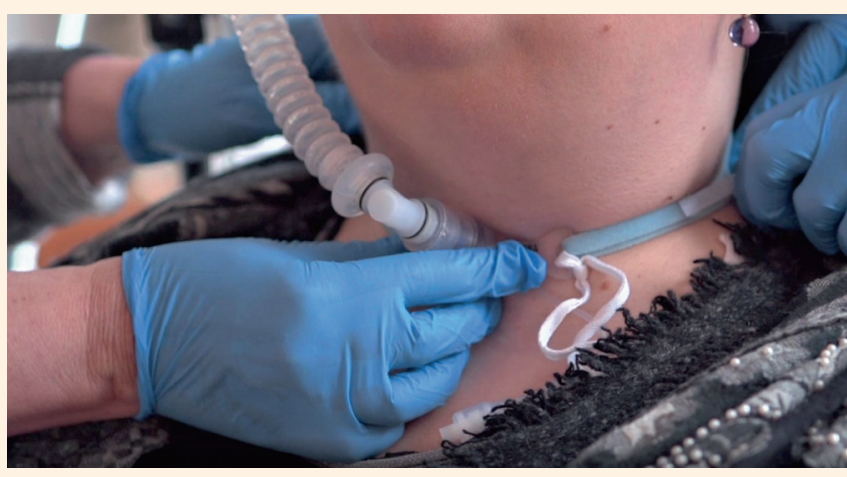

- Vervang zo nodig het fixatiemateriaal. Zorg dat het bandje niet te strak zit, met het oog op drukletsels. Er moet makkelijk een vinger tussen huid en fixatiemateriaal kunnen.

- Aspireer indien nodig (zie volgende handeling).

- Reinig de canule. Gebruik voor de binnenzijde een canuleborsteltje of een pincet met gaasje. (Bij gebruik van ontsmettingsvloeistof spoel je hem daarna af.) verzorgen deze patiënten met spatbril en gewoon chirurgisch masker. Tijdens de wondzorg vervang je de vuile binnencanule door een schone. $\mathrm{Na}$ de wondzorg heb je dan de tijd om de gebruikte canule te reinigen en klaar te leggen voor de volgende wissel.

De herbruikbare binnencanule reinigen we tweemaal per dag. Een disposable canule vervangen we eenmaal per dag of in de thuiszorg om de 2 dagen om de kostprijs voor de patiënt niet te laten oplopen.* Daarom gebruiken we ook zoveel mogelijk herbruikbare canules. Het fixatiebandje vervangen we dagelijks of vaker indien vervuild. Het verzorgen van de stoma doen we dagelijks, maar niet kort na een maaltijd om het risico op braken te beperken.'

\section{Wondzorg}

Meestal geeft de wondzorg weinig problemen, al is het beschermen van de huid tegen vochtletsel een continu aandachtspunt. Daarom breng je een splitgaas of een Metalline kompres onder het uitwendige deel van de tracheacanule tegen de huid aan. Je knipt niet zelf een gaaskompres in, omdat de vezeltjes daarvan in de trachea terecht kunnen komen. Het doel van een splitgaas is het opvangen van sel vertonen, dat je aanstipt met zilvernitraat.

\section{Controle van de cuff}

Bij een gecuffte canule controleer je regelmatig de cuff, twee- tot driemaal

\section{'Knip niet zelf een gaaskompres in, omdat de vezeltjes daarvan in de trachea terecht kunnen komen'}

vocht en het voorkomen van drukletsels. Wanneer dat bij een tracheacanule die al een hele tijd aanwezig is geen probleem meer vormt, mag je het splitgaas weglaten. Dat kan de kostprijs voor de patiënt drukken (in België). Vochtletsels voorkomen kan ook door het gebruik van bijvoorbeeld Cavilon ${ }^{\circledR}$ swab of crème rond de stoma. Verder kan een tracheostoma kort na de aanleg wat granulatieweef- per dag met een cuffdrukmeter. Je let er bijvoorbeeld op dat hij niet te hard opgeblazen is, zodat er geen drukletsels ontstaan ter hoogte van de tracheamucosa. De druk in de cuff mag niet hoger zijn dan 25 tot $30 \mathrm{mmHg}$. Hiervoor breng je 5 tot $10 \mathrm{ml}$ lucht in de cuff. Je laat de cuff regelmatig af en blaast die weer op (volgens protocol van je instelling) om inwendige drukletsels te voorkomen. Die kunnen op 
CLL van loghum

CSS bohn 7) stafleu

1. van loghum

cce bohn

9 stafleu

CL van loghum

cCe bohn

stafleu
van loghum

cCohn bohn

D) stafleu

van loghum

$\int S$ bohn

C. van loghum

cCe bohn

9) stafleu

van loghum

SCS bohn

CL van loghum

CSS bohn

¿stafleu van loghum

SSS bohn

van loghum
\& stafleu

van loghum

$\iint \begin{aligned} & \text { bohn } \\ & \text { stafleu } \\ & \text { van loghur }\end{aligned}$

van loghum

SSS $\begin{aligned} & \text { bohn } \\ & \text { stafleu }\end{aligned}$

van loghum

CSS bohn

stafleu

van loghum

$\int S$ bohn

1. van loghum

CSS bohn

stafleu

$\int S$ bohn

van loghum

SCS bohn

stafleu

van loghum

CS bohn

stafleu

CS bohn

CL van loghum

SCS bohn

stafleu

van loghum

SCS bohn

8 stafleu

van loghum

$\iint \begin{aligned} & \text { bohn } \\ & \text { stafleu } \\ & \text { van loghum }\end{aligned} \quad$ SC $\begin{aligned} & \text { bohn } \\ & \text { stafleu } \\ & \text { van loghum }\end{aligned}$
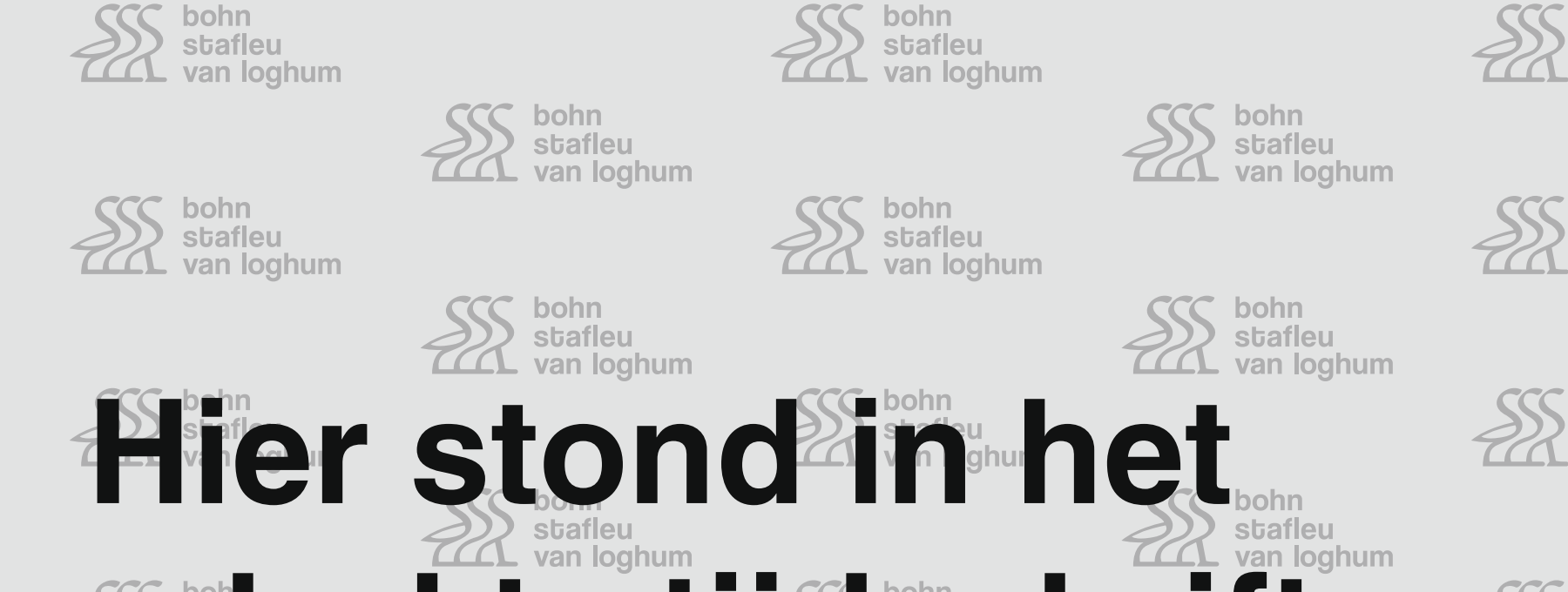

CSS bohn

Psafleu

van loghum

CSS bohn

8 stafleu

cL van loghum

SSS bohn

8 L van loghum

CSS bohn

$8 \int$ stafleu

1. van loghum

SSS bohn

CL van loghum

CSS bohn

S) stafleu

SSS bohn

van loghum

CCS bohn

S) stafleu

CL van loghum bohn

stafleu

van loghum

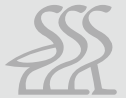

SCS bohn

SS stafleu van loghum

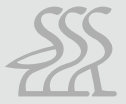

CSS bohn

stafleu

van loghum

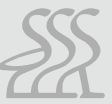

CSS bohn

S) stafleu van loghum

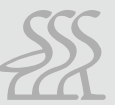

SSS bohn van loghum 
UITZUIGEN VAN EEN TRACHEACANULE OP EEN VERPLEEGAFDELING OF IN DE WIJK

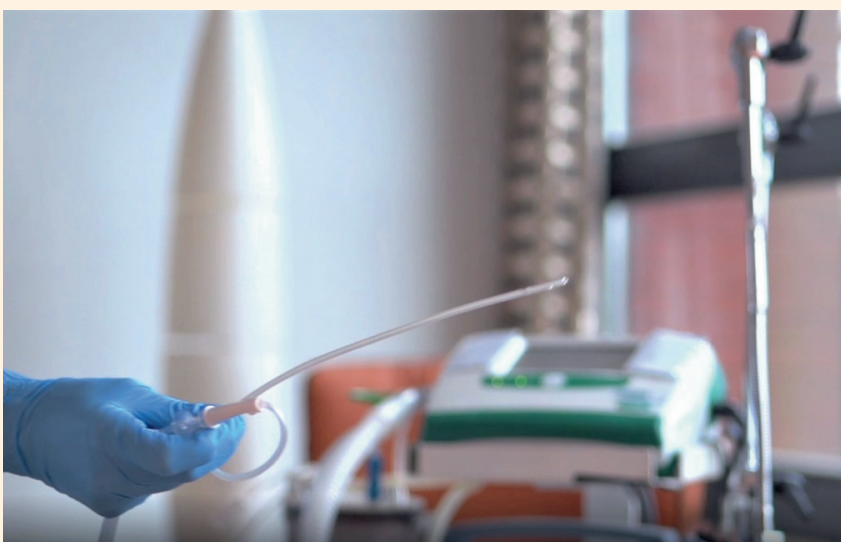

- Was en ontsmet je handen en doe niet-steriele handschoenen aan. Zet mondmasker en spatbril op volgens het protocol van de instelling of organisatie.

- Verzamel de materialen. Informeer de patiënt, installeer hem in een halfzittende houding of een comfortabele rugligging.

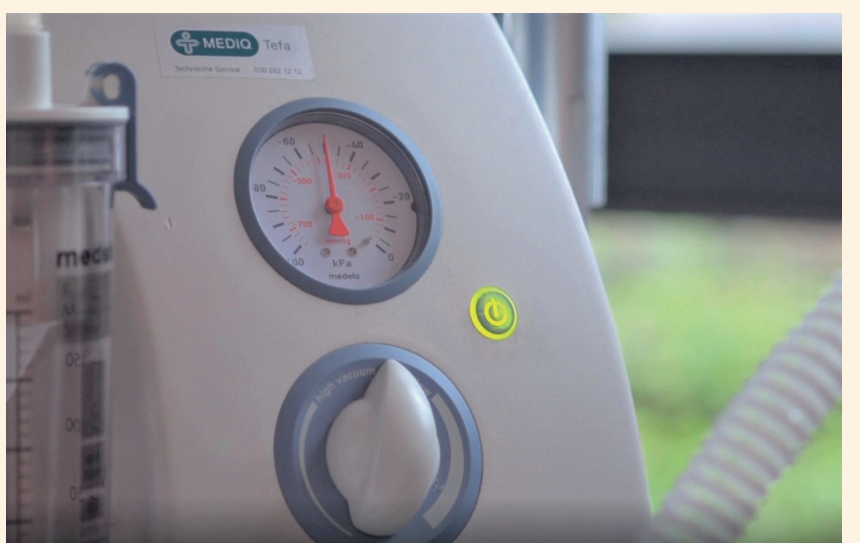

Controleer de zuigkracht van het aspiratietoestel door het aspiratietoestel aan te zetten, de verbindingsslang van het toestel dicht te klemmen en op de drukmeter te kijken of de zuigkracht oploopt (zoals op de foto).

- Bij een gevensterde canule: plaats een inwendige canule zonder venster.

- Vraag de patiënt om enkele keren diep in en uit te ademen voor de start van aspiratie.

- Breng een steriele uitzuigkatheter aan op de verbindingsslang van het aspiratietoestel en start de zuigkracht.

\section{Materialen aspireren}

- Steriele wegwerpaspiratiesonde voor het uitzuigen van een tracheostoma

- Aspiratietoestel en -katheter(s)

- Een schone binnencanule en een bekken voor de gebruikte binnencanule

- Water

- Niet-steriele handschoenen, mondmasker, spatbril

termijn een tracheastenose en dus een blijvende beschadiging aan de trachea veroorzaken. De cuff aflaten en weer opblazen veroorzaakt een hoestreflex bij de patiënt. Let er zoals gezegd op dat hij de tracheacanule op dat moment niet uithoest. Daarnaast zijn er ook canules met een cuff die je met water moet vullen. Hierbij volg je de voorschriften van de arts. Die cuffs zijn niet te controleren met een cuffdrukmeter.

\section{'Te diep of te langdurig uitzuigen zijn de meest voorkomende fouten'}

\section{Aspireren}

'Het is belangrijk om het aspireren of uitzuigen zo kort mogelijk te laten duren om de ademnood bij de patiënt te beperken', legt Leen Backaert verder uit. 'Bij het aspireren brengen we de aspiratiesonde/uitzuigkatheter in over de lengte van de canule, 10 tot $12 \mathrm{~cm}$. Ga niet zover tot je weerstand voelt, want dan kan de zuigkracht het slijmvlies aan de binnenwand van de trachea beschadigen en littekenvorming veroorzaken. Te diep en/of te langdurig uitzuigen zijn de meest voorkomende fouten.'

Sander Steijns vervolgt: 'Een ander veel gemaakte fout is het niet respecteren van de steriliteit van de laatste $15 \mathrm{~cm}$ van de zuigkatheter. Je mag met die zone voor het inbrengen niets aanraken, ook je handen niet.' Je mag wel het uitzuigen herhalen met dezelfde steriele katheter en de katheter ook gebruiken om, na het uitzuigen van de trachea, de neus en de mond van de patiënt te aspireren, maar niet omgekeerd. Beperk het uitzuigen tot 10 tot 15 seconden om de patiënt niet nodeloos in ademnood te brengen. De zuigkracht ligt op 150 $\mathrm{mmHg}$ of -40 en $-60 \mathrm{kPa}$. De diameter van de zuigkatheter is ongeveer de helft van de interne diameter van de tracheacanule en ligt tussen de $\mathrm{Ch} 8$ en 14 .

Tijdens het aspireren observeer je de patiënt op onrust, ademnood en huidskleur en het aspiraat op hoeveelheid, kleur, consistentie, geur, aanwezigheid van bloed of voedsel. 
CLL van loghum

CSS bohn 7) stafleu

1. van loghum

cce bohn

9 stafleu

CL van loghum

cCe bohn

stafleu
van loghum

cCohn bohn

D) stafleu

van loghum

$\int S$ bohn

C. van loghum

cCe bohn

9) stafleu

van loghum

SCS bohn

CL van loghum

CSS bohn

¿stafleu van loghum

SSS bohn

van loghum
\& stafleu

van loghum

$\iint \begin{aligned} & \text { bohn } \\ & \text { stafleu } \\ & \text { van loghur }\end{aligned}$

van loghum

SSS $\begin{aligned} & \text { bohn } \\ & \text { stafleu }\end{aligned}$

van loghum

CSS bohn

stafleu

van loghum

$\int S$ bohn

1. van loghum

CSS bohn

stafleu

$\int S$ bohn

van loghum

SCS bohn

stafleu

van loghum

CS bohn

stafleu

CS bohn

CL van loghum

SCS bohn

stafleu

van loghum

SCS bohn

8 stafleu

van loghum

$\iint \begin{aligned} & \text { bohn } \\ & \text { stafleu } \\ & \text { van loghum }\end{aligned} \quad$ SC $\begin{aligned} & \text { bohn } \\ & \text { stafleu } \\ & \text { van loghum }\end{aligned}$
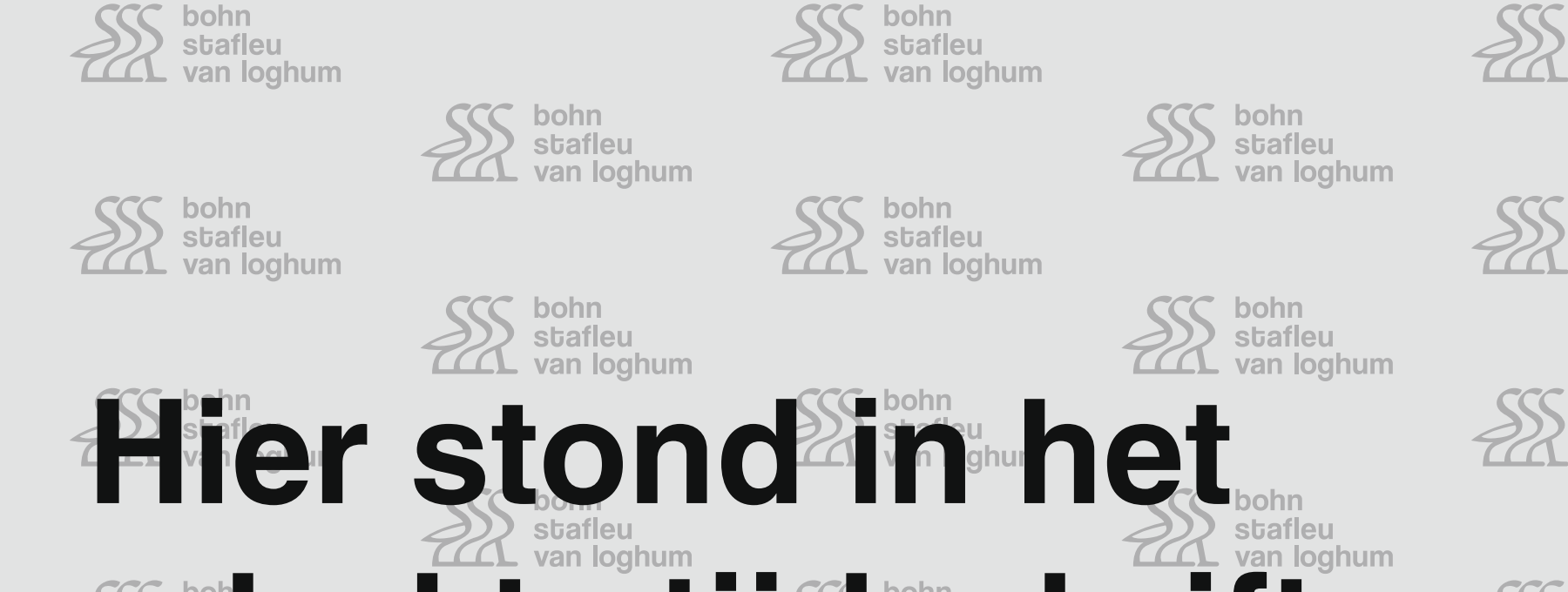

CSS bohn

Psafleu

van loghum

CSS bohn

8 stafleu

cL van loghum

SSS bohn

8 L van loghum

CSS bohn

$8 \int$ stafleu

1. van loghum

SSS bohn

CL van loghum

CSS bohn

S) stafleu

SSS bohn

van loghum

CCS bohn

S) stafleu

CL van loghum bohn

stafleu

van loghum

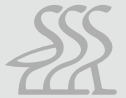

SCS bohn

SS stafleu van loghum

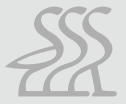

CSS bohn

stafleu

van loghum

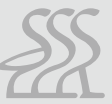

CSS bohn

S) stafleu van loghum

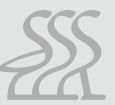

SSS bohn van loghum 


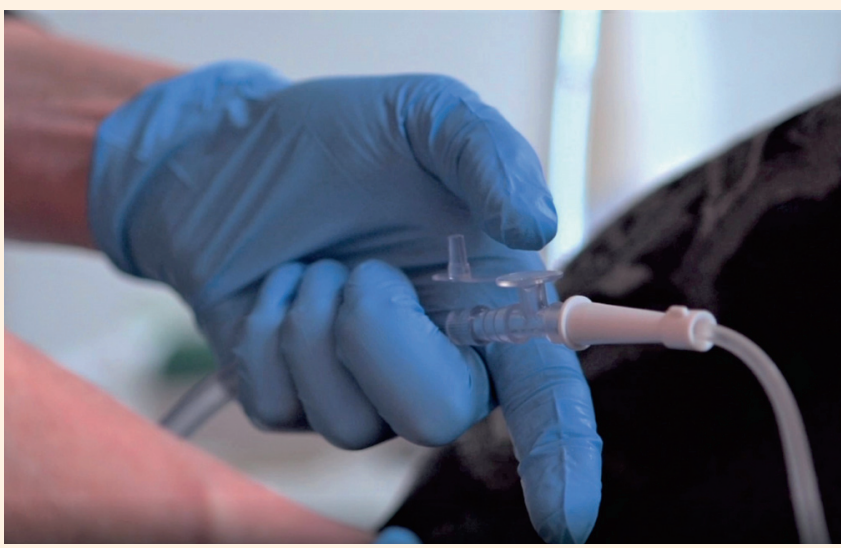

- Open de tracheacanule. De binnencanule hoef je niet te verwijderen.

- Breng de aspiratiesonde traag en zonder aspiratie, met open vingertipcontrole, in de canule over een afstand van 10 tot $12 \mathrm{~cm}$. Stop als de patiënt hoest of als je weerstand voelt. Trek dan de aspiratiesonde 1 tot 2 centimeter terug.

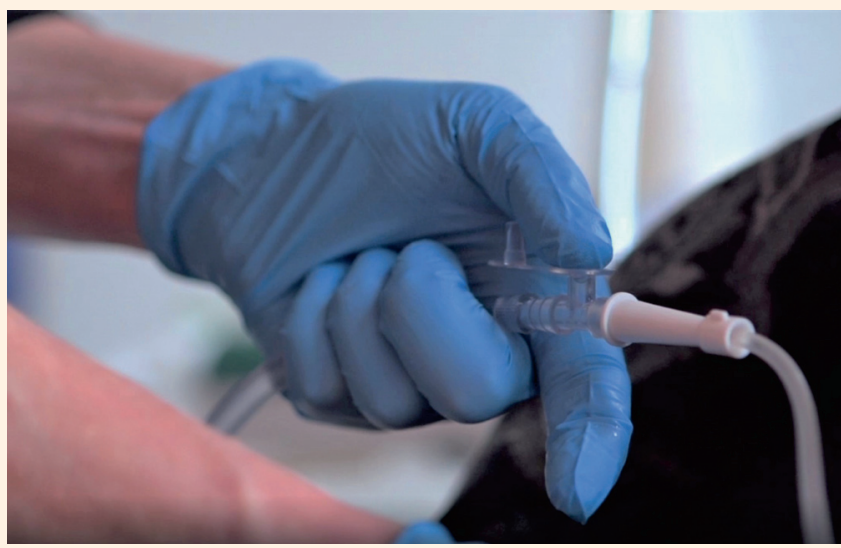

- Sluit met je vinger de vingertipcontrole: daardoor start de aspiratie. Trek de sonde langzaam, eventueel intermitterend, met een draaiende, roterende beweging terug. Observeer het sputum.

- Indien nodig herhaal je de aspiratieprocedure, maar laat de patiënt eerst even diep in- en uitademen. Tussen 2 aspiraties laat je minstens 30 seconden.

- Sluit de tracheacanule door de gesloten binnencanule, spreekknopje, afsluitdopje, beademingsslang of kunstneus terug te plaatsen.

- Verwijder de zuigkatheter en spoel de verbindingsslang en de vingertipcontrole door met water.

- Observeer de patiënt en ga na of alles in orde is. Ruim de materialen op, trek de handschoenen uit en was/desinfecteer de handen.

\section{Tracheacanule thuis}

'Wanneer een patiënt de afdeling met een tracheostoma verlaat, bekijken we de educatiemogelijkheden van de patiënt en zijn familie en zo nodig schakelen we thuisverpleging in,' aldus Backaert. 'We informeren hen en geven een brochure met informatie en contactgegevens mee. Het aspireren thuis proberen we tot een minimum te beperken, vanwege het risico op beschadiging van de luchtweg en infecties, en omdat aspireren vaak een vals gevoel van veiligheid geeft. Het is belangrijker dat een patiënt sputa goed en krachtig leert ophoesten om zijn luchtweg vrij te houden. Bij een patiënt met een spierziekte of met een dwarslaesie kan dat laatste niet en is aspiratie nodig.'

\section{'De laatste $15 \mathrm{~cm}$ van de zuigkatheter moet steriel blijven, je mag er niets mee aanraken'}

Steijns vult aan: 'Je aspireert een patiënt wanneer hij dat aangeeft, wanneer je hoort dat zijn ademhaling belast is, of wanneer er een beademingsalarm afgaat. Aspireer inderdaad zo min mogelijk, ook om prikkeling van de luchtwegen te voorkomen, want dat veroorzaakt juist meer slijmvorming.

Met dank aan Bregje Frickx, kinesitherapeute, Medisch Intensieve Zorgen UZ Leuven.

\begin{abstract}
Noten
* Noot voor Nederlandse lezers: in Vlaanderen betalen patiënten de canules gedeeltelijk zelf.

- Vander Poorten V. Tracheotomie, tracheostomie, tracheostoma. In: Cordyn S, De Vliegher K (red.). Handboek wondzorg. Houten: Bohn Stafleu van Loghum, 2016, pp. 209-222.

- E-learning, protocollen en meer: Onderwijsprogramma Chronische beademing: www.ctbscholing.nl.

- Video Zorg-Wijs: www.youtube.com/ watch? $v=F m c 4 Z Q G$ tidw. Deze link vind je in de online versie van dit artikel op Nursing.nl, thema Verpleegtechnische handelingen
\end{abstract}

